\title{
Research on the Characteristics and Realization Mechanism of National Traditional Sports Fitness Under the Background of Healthy China
}

\author{
Chunquan Zhu \\ Sports Department, Sichuan Vocational and Technical College, Suining, China
}

Email address:

1010119554@qq.com

To cite this article:

Chunquan Zhu. Research on the Characteristics and Realization Mechanism of National Traditional Sports Fitness Under the Background of Healthy China. Higher Education Research. Vol. 5, No. 5, 2020, pp. 167-173. doi: 10.11648/j.her.20200505.11

Received: August 9, 2020; Accepted: August 19, 2020; Published: August 27, 2020

\begin{abstract}
This paper studies on the problem of national traditional sports fitness under the background of healthy China, using the method of literature and logical analysis. It says that the strategy of healthy China objectively requires Chinese people to master the basic characteristics of national traditional sports and establish a sound and effective fitness mechanism in line with the characteristics of national culture. It is suggested that by strengthening the top-level design of sports health, the public fitness system of national traditional sports should be constructed; through the development of modern sports health industry, the national traditional sports fitness activities should be scientifically positioned by sports prescription; the national culture of sports health should be carried forward to enrich the spiritual content of national traditional sports fitness. On this basis, to achieve the overall shaping of national traditional sports fitness. Preface: National traditional sports is the product of the times, with tenacious vitality and cohesion, and plays an important role in the inheritance and development of national culture. Under the background of healthy China strategy, on the one hand, the national traditional sports will be inherited, carried forward and integrated into the national fitness activities, which has a direct role in strengthening the people's physique and improving the fitness level. On the other hand, combining the national traditional sports and the characteristics of the times will be combined to constantly enrich its connotation, establish the Chinese standard of sports health and strengthen cultural confidence [1]. National Traditional Sports and public fitness must be organically integrated, which can not only achieve scientific fitness, but also enhance national consciousness and national spirit. As an important part of Chinese sports culture, the inheritance of national traditional sports has an internal positive role in improving social health and realizing the national self-improvement. At the same time, the scientific development of national traditional sports and the promotion of national traditional sports industry will be an important driving force for the new development of national traditional sports in the new era.
\end{abstract}

Keywords: Healthy China, National Traditional Sports, Health Value, Realization Mechanism

\section{Background}

Healthy China is an important concept put forward by general secretary Xi Jinping in August 2016 in "healthy China". He stressed that health is the "1" of life's success and accomplishments, while family, career and wealth are " 0 " after "1". Only "1" stands tall, and many " 0 " after that are arranged. Everything in good order and well arranged in the nineteen major reports of Xi Jinping, October 2017, is the important symbol of national prosperity and national prosperity. We should improve the national health policy and provide the people with a full range of full cycle health services. We should systematically promote the implementation of the healthy China strategy. In July 2019, China issued "healthy China action (2019-2030)" and other documents to vigorously promote the implementation of the healthy China strategy.

\section{Literature Review}

Health has always been the most important livelihood issue of the Party Central Committee and the people. Especially since the healthy China strategy was put forward, healthy China and people's health have become the hot spot of 
academic research. Scholars have discussed and studied the healthy China strategy from various dimensions, and interpreted the profound connotation of the healthy China strategy. Among them, Wu Haiying [2], Li Hongwen [3] and other scholars studied the contemporary concept of health from the perspective of mental health and social factors; Chen Zhu, Gao Qiang [4], Li Tao, Wang Xiufeng [5] studied the profound connotation of healthy China strategy; Peng Guoqiang [6], Han Xiping, sun Xiaojie [7] and other scholars studied the implementation path methods. From the research content, scholars mainly from the policy interpretation, medical and health, sports fitness and other aspects of multi-dimensional elaboration and research, mainly focusing on basic theoretical research. Starting from the national traditional sports, this paper mainly studies its fitness characteristics and realization mechanism, with a view to establishing a sound and effective fitness mechanism in line with the characteristics of national culture, building a public fitness system of national traditional sports, scientifically positioning the national traditional sports fitness activities with sports prescription, so as to achieve the overall shaping of national traditional sports fitness.

\section{The Origin and Essence of Healthy China}

The proposal and implementation of the strategy of healthy China is not only related to the background of the times, but also consistent with the idea of "prevention of disease" emphasized in traditional Chinese health culture [8]. On the one hand, since the reform and opening up, China's economy has developed at a high speed, and the living standards of residents have been gradually improved. Chronic diseases such as diabetes, hypertension and hyperlipidemia account for a large proportion of the population. The incidence of these chronic diseases is also gradually showing a younger trend, which brings pressure to the overall health cause of our country. Especially in the information age of high complexity and high uncertainty, residents of different ages are busy with their families, studies and careers. High intensity pressure, irregular work and rest, diet and so on have become one of the important factors affecting health. On the other hand, Chinese traditional health culture emphasizes the way of "preventing disease" to find out the hidden danger of health and solve the problem. It can be said that the strategy of healthy China not only conforms to the times, but also reflects the long history of Chinese excellent traditional culture.

The implementation of healthy China is inseparable from the cultivation of residents' healthy lifestyle. In other words, the essence of healthy China is a healthy lifestyle of residents, so it can obtain a deep mass foundation [9]. The healthy lifestyle of residents can be developed by enhancing health knowledge, regular work and rest, balanced diet, daily exercise and so on. First, residents of different ages should consciously learn basic health knowledge and common sense of health, so as to maintain health and nourish the mind in daily life. For teenagers, it is necessary to make themselves understand the changes of their bodies, and judge their own physical development and health through relevant indicators. For the middle-aged group, to learn prevention and self-care knowledge, can be more sensitive to find their own body changes, problems can be solved as soon as possible. For the elderly, it is necessary to maintain the communication with friends and family around them, and also to keep learning in their own way to understand the relevant health knowledge. Second, regular work and rest. The cultivation of a good lifestyle is inseparable from the cultivation of regular work and rest. Residents of all ages should avoid bad habits such as staying up late. Human organs have different periods of detoxification. Staying up late for a long time will cause some organs to have poor detoxification and affect their health. Third, a balanced diet. Traditional Chinese medicine believes that "food therapy" is a good way of health preservation, but also a good way to "prevent disease". Therefore, three meals should be on time, balanced, daily intake of all kinds of nutrients needed by the body to enhance resistance. Fifthly, strengthen exercise and keep fit. Exercise helps to dredge muscles and bones and relieve pressure. Residents of different ages should form good exercise habits and realize the freedom and health brought by self-discipline in the process of fitness.

Generally speaking, the strategy of healthy China objectively requires Chinese people to master the basic characteristics of national traditional sports and establish a sound and effective fitness mechanism in line with the characteristics of national culture, so that this fitness mechanism not only conforms to the scientific law of sports health, but also highlights the Chinese characteristics of multi-ethnic culture. In fact, the national traditional sports is also a set of concise about residents' healthy lifestyle.

\section{Connotation and Structural Type of National Traditional Sports}

Chinese traditional sports is a splendid landscape of multi-ethnic culture in China. The National Traditional Sports in our country are not only sports activities, but also the important media and components of agricultural activities, religious activities, wedding activities and war activities. After a long history of precipitation, national traditional sports gradually separated from the reality of religious activities, war activities, and maximize the preservation of education, entertainment and other cultural factors. Therefore, the national traditional sports is in fact a comprehensive cultural form which highlights the educational and recreational functions created by various nationalities.

National traditional sports is the product of the production and life practice of various nationalities. Only when the national traditional sports are closely related to the production and life practice of various nationalities can its traditional significance and unique value be retained. As an important medium and component of cultural display, National Traditional Sports express and symbolize the common values 
and behavior modes of all ethnic groups in China. All ethnic groups also maintain and confirm their own continuity through national traditional sports, and realize their own social reconstruction in modern times. The traditional sports characteristics, which are derived from traditional sports of Han nationality and traditional sports of ethnic minorities, lead the spirit of Chinese culture to advance step by step and become the externalization mode of traditional national spirit. Therefore, the national traditional sports has a stable cultural structure, which gathers and stores the symbols, languages and images of national sports, retains the unique style of national activities, and shows the historical evolution process of national physical activities.

There are many traditional national sports, nearly a thousand in number, and they are too numerous to enumerate in form. For example, Han martial arts, Mongolian horse racing, Miao drum racing, Li bamboo jumping, Tibetan getun. They are well-known national traditional sports. From the perspective of the theoretical system construction of sports discipline, domestic scholar Luo Yimin proposed that national traditional sports should be classified into four types: martial arts, fitness Qigong, Chinese wrestling and Chinese folk sports [10]. However, its classification standard to a certain extent obscures the diversity of traditional ethnic sports forms, especially does not highlight the important value of ethnic traditional sports. From the perspective of the development and change of national traditional sports, domestic scholar Zhao Su Zhe divided the national traditional sports into three stages: fossil type, primitive type, development stage type, relatively mature type and mature type [11]. The classification standard put forward by Zhao Su Zhe is of great significance for the comparative study of national traditional sports, but the classification of national traditional sports types is still too vague.

Based on the literature analysis, author believes that from the existing functions and characteristics, the national traditional sports mainly include folk festival traditional sports and health guidance practice sports, which can basically cover national traditional sports. First of all, folk festival traditional sports is a general summary of the traditional sports forms of Han and ethnic minorities, reflecting the basic features of traditional ethnic sports and sports forms. Secondly, health guidance practice sports is the cognition and summary of the characteristics of modern mainstream national traditional sports (martial arts, qigong, chess), which also reflects the Chinese cultural character and spiritual pursuit.

\section{Fitness Characteristics and Health Value of National Traditional Sports}

\subsection{Fitness Characteristics of National Traditional Sports}

\subsubsection{Integration of Spirit and Form}

National traditional sports has always been a part of Chinese traditional culture, which contains profound national culture. Traditional national sports are not limited to physical activities, but often have more profound humanistic connotation. Therefore, the combination of external form and internal spirit is inseparable. For example, Chinese culture stresses "the unity of man and nature" and pursues the harmony and unity of man and nature. Traditional national sports inherit this spiritual connotation. Taking Taijiquan, which is well-known to all, as an example, its practice stresses "no movement, no loosening", comprehensive body exercise, all-round exercise of essence, Qi and spirit, and the pursuit of the state of unity of God and form and unity of nature and man. Seemingly simple sports, in fact, are all-round training and promotion of the body and spirit of the practitioner. The form and spirit are the exterior and interior of each other, complement each other, and have inseparable integrity. "The integrity of the unity of spirit and form" side also shows that national traditional sports is a high-grade form of fitness activities [12].

\subsubsection{The Initiative of Pluralistic Opening up}

Chinese culture is a pluralistic, open and inclusive civilization, which has become an important reason for its long-term survival and continuous growth and innovation. As an important part of this civilization, national traditional sports have fully inherited this excellent gene. National traditional sports can be said to contain a variety of sports activities: martial arts, wrestling, lion dance, diabolo It has various forms and names, and the list is still expanding and bringing forth new ones. Taking the most common Taijiquan as an example, in addition to the Chen, Yang, $\mathrm{Wu}$, sun and other factions, it also includes sword, knife, gun, fan and other equipment. People constantly explore every possibility, which can be called the representative of pluralism and openness. Since modern times, Huo Yuanjia founded the Jingwu gymnastics club to spread martial arts. With an open and self-improvement mentality, Huo Yuanjia learned from all kinds of schools, absorbed all kinds of things, sought innovation and change, and explored actively, which had a far-reaching influence. This multi-element and open initiative makes the national traditional sports provide enough choices for learners and benefit every national traditional sports fan.

\subsubsection{Safe and Flexible Entertainment}

One of the outstanding advantages of national traditional sports is that it not only strengthens the body, but also takes into account the entertainment, with low risk and strong flexibility. For example, Taijiquan is suitable for all ages. Its slow rhythm and elegant moves make it easy for practitioners to immerse themselves in it and enjoy their body and mind. This slow rhythm also determines that the sport is not easy to cause sports injuries, but also in a large extent to avoid accidental injuries. And this kind of fun realization cost is extremely low, the square, the park, even is own courtyard, the living room can, very flexible. National Traditional Sports tend to group sports, which can stimulate each other and make progress together, and achieve mutual resonance in the process of pursuing orderliness and coordination, which makes sports have certain entertainment. Group sports further strengthen the entertainment, through the low-intensity confrontation between each other, can deepen the 
understanding of their own skills, so as to practice more assiduously. The traditional sports of various nationalities, such as diabolo, lion dance and so on, often have the above characteristics.

\subsection{Health Value of National Traditional Sports}

The goal of the Chinese nation is to prevent disease. The significance of systematic and unremitting national traditional physical exercise lies in the continuous polishing and continuous improvement of the body, so as to achieve the purpose of strengthening the body. Traditional national sports can often improve the physical quality of learners in many ways, not only can exercise the body muscle group, enhance strength, enhance flexibility, improve coordination, but also can increase lung capacity, make the heart and lung function more powerful. Systematic and targeted exercises can also promote blood circulation and metabolism, and have a good prevention and mitigation effect on cardiovascular and cerebrovascular diseases. Practitioner of traditional Chinese medicine says "prevention of disease" means that prevention is the first and treatment is the second. In fact, the promotion of national traditional sports has also played such a role to a certain extent. If a person is strong, the probability of natural infection will be reduced, which is another form of "preventive treatment".

\subsubsection{Sharpen Spirit and Increase Endurance}

Traditional national sports are not only physical exercise, but also the tempering of individual spirit. The so-called "exercises in cold winter and in hot summer" refers to this kind of unremitting exercise process, such as the "standing pile" of Taiji and the "horse riding step" in martial arts. The long-term persistence is not only a great test of physical fitness, but also the ultimate grinding of individual spiritual strength. The corresponding results are the enhancement of mental toughness and the improvement of individual endurance, so as to improve the individual body from the inside to the outsid.

\subsubsection{Pleasant Body and Mind}

At the same time, there are quite a number of national traditional sports that can achieve the effect of body and mind pleasure by regulating the breathing, rhythm and blood circulation of the practitioners. It can be said that the national traditional sports not only "cultivate one's moral character", but also "cultivate one's nature". Through the combination of inside and outside, people can keep a peaceful state of mind, keep the body in a relatively stable cycle state and keep healthy.

\subsubsection{Promote the National Physical Fitness}

National traditional sports are deeply rooted in the hearts of the people. It exists in every corner of the city and the countryside in various forms. It is a spontaneous group activity. In this process, the unremitting efforts of individuals and the mutual stimulation of groups are of great significance to the improvement of national physical quality. It can be said that the learners have achieved the effect of strengthening their health by means of low cost, low risk and flexible forms.
If this effect is amplified, it will be a great improvement of the national physical quality of a community, a national region and even a country.

\section{The Realization Mechanism of National Traditional Sports Fitness from the Perspective of Healthy China}

\subsection{Strengthen the Top-level Design of Sports Health and Build the Public Fitness System of National Traditional Sports}

\subsubsection{Adhere to the Government's Leading Role and Promote the Integration of National Traditional Sports and Public Fitness}

Due to its unique fitness effect, fine traditional customs and unique national style, the national traditional sports have been inherited continuously in the course of human development, and continue to this day. However, with the rapid development of today's economy, the acceleration of the pace of life and the erosion of western commercial sports, people put more time and energy into the economic pursuit, and the understanding of national traditional sports is becoming more and more weak, which leads to the marginalization of the inheritance of national traditional sports in national life. In order to enhance people's awareness of fitness, in recent years, the state has implemented the "healthy China 2030" program. With the support of this policy, the development of democratic traditional sports has entered a new period. First of all, national traditional sports are the soul of our nation. In order to make them better integrated with the objective laws of economic and social development in China, we should remove the dross and extract the essence, and remove it from the areas which are not suitable for the development of today's society, and retain the essence part, so that it will not only be loved by the Chinese people, but also be welcomed by international friends. Secondly, the relevant government departments should carry out overall design and planning for the development of national traditional sports [13], strengthen the relevant support of policies and funds, apply traditional sports to all aspects of life, establish corresponding venues and equip special equipment according to the local economy and the acceptability of people, so as to improve the enthusiasm of people for traditional sports and satisfy everyone. Finally, in order to further strengthen the correctness of the application of traditional sports, it is necessary to regularly organize face-to-face communication between experts and scholars in national traditional sports science and humanities sociology and other disciplines, and conduct irregular telephone interviews to conduct in-depth exchanges on controversial issues, so as to enhance people's cognition and understanding of the relationship between traditional sports and physical health.

\subsubsection{Promote the Coordinated Development of National Traditional Sports and School Sports, and Shape the Healthy Body and Mind of Teenagers}

The development of national traditional culture needs the joint efforts of contemporary people and the next generation. 
Integrating the national traditional sports culture into the physical education of teenagers can deepen the spiritual connotation of teenagers, expand the connotation of teenagers' life, and better inherit it to the maximum extent. At the same time, it can also add new contents in the history of human spiritual civilization. The coordinated development of national traditional sports and school sports is conducive to the cultivation of national consciousness and national spirit of teenagers. Traditional sports culture is the product of the times, which can promote the inheritance and development of national culture, and plays an important role in the inheritance and promotion of traditional sports culture. First of all, we should set up the relevant national traditional sports according to different ages, set up the relevant theoretical knowledge teaching, enrich the school physical teaching content, so that students can master the correct fitness thought and cultural connotation; secondly, organize video teaching for students, on the basis of theoretical understanding, make students complete the imitation and review of the video, and make technical correction to students. In order to stimulate students' enthusiasm in traditional sports, male students can choose from traditional sports courses such as horse racing and wrestling, and girls choose swing and springboard. Finally, organize relevant sports competitions for students to provide certain rewards for outstanding students. In addition, it can also organize sports competitions between different schools, so as to further strengthen students' enthusiasm for learning. In short, national traditional sports culture plays an important role in cultural heritage, promotion and education of Chinese civilization. National traditional sports should be an important way for Chinese teenagers to exercise their physique and achieve healthy physical and mental health.

\subsection{Develop the Industry of Sports Health and Scientifically Position the National Traditional Sports Fitness Activities}

\subsubsection{Vigorously Develop the Industry of Sports Health and Promote the Upgrading of National Traditional Sports Industry}

Today, the pace of people's life is speeding up, and the social competition is becoming increasingly fierce. The social risk competition (loss, anxiety, depression and frustration) is becoming increasingly fierce. Sports play an important role in leisure, entertainment, physical and emotional experience, which can promote people to have a confident and optimistic attitude towards life and enhance their sense of happiness for life. As an important industry to maintain the physical and mental health of the whole people, sports industry not only plays an important role in improving human sub-health, but also plays an important role in maintaining national prosperity and promoting economic and social development. Thus, it can be seen that developing the industry of sports health is the most important task at present. It is necessary to promote the upgrading of national traditional sports industry so that it can obtain new development in the new period, and then meet the health needs of contemporary people. First of all, it is necessary to build professional traditional national sports venues, set up professional training bases and comprehensive sports service items in the venues, and on this basis, promote the construction of national sports resource database [14]. Among them, we should try to get rid of the monotonous scene setting in the stadium, follow the guidance of market trend and cultural trend, and inject rich and high-quality fitness and leisure services into the stadiums; secondly, the national traditional sports industry and other economic industries should be organically combined to break the development obstacles of National Traditional Sports mode, and promote national traditional sports, health culture, medical care, etc The cross-border integration of various industries will integrate the upstream and downstream resources of the industry, so as to further build the supply chain of fitness and leisure industry, and let consumers experience the one-stop service of health and entertainment. Finally, close cooperation between national traditional sports service institutions should be strengthened. Different sports service institutions should always share resources, cooperate and support each other. We should develop the win-win strategy of market economy, change the single supply mode, and form a diversified supply mode through mutual assistance, so as to promote the upgrading of national traditional sports industry and maintain the long-term development of traditional sports industry.

\subsubsection{Scientifically Develop National Traditional Sports, Promote Comprehensive Fitness Activities}

National traditional sports is the product of the development of a specific historical period. In its development and formation process, it was deeply affected by traditional customs, traditional morality, traditional education and other related traditional cultural forms, with its independent cultural form. Therefore, we need to develop the national traditional sports scientifically in the practical application. First of all, in order to ensure the scientific development of national traditional sports, we should strengthen people's theoretical cognition of national traditional sports. Due to the departure of the old artists who master the various items of national traditional sports, the loss of traditional sports culture is serious, and people's cognition of traditional sports has become more and more fuzzy. Therefore, it is necessary to regularly setting up relevant theoretical seminars, such as face-to-face professional consultant, relevant knowledge competitions, etc.; secondly, we should formulate corresponding traditional sports for different ages, and can not adopt one size fits all approach Policy, so that the traditional sports to the maximum extent to serve the people's livelihood, meet people's high-level health needs, create a good atmosphere for national fitness, so that sports emerged into life; finally, in the process of developing traditional sports, we should pay attention to the mutual integration of culture. Because the traditional sports have been developing in a certain era, we can not blindly copy the ancient sports under the condition of not changing the main body of traditional sports. We should pay attention to absorbing foreign culture, promote cultural innovation and integration, and make traditional sports adapt to the objective law of current economic development. 


\subsection{Carrying Forward the Healthy National Culture of Sports and Enrich the Spiritual Content of National Traditional Sports Fitness}

\subsubsection{Carrying Forward the National Culture of Sports Health and Establish the Chinese Standard of Sports Health}

China has a long history and splendid national culture. As the only four ancient civilizations with uninterrupted history, China has been leading the development of world culture in the long history. As an important part of China's excellent traditional culture, China's sports culture is essentially different from western countries' sports culture. It contains the characteristics of our Chinese nation. It has been precipitated in the process of historical development. It carries the wisdom of the working people, has profound cultural heritage, and endows our nation with a unique concept of physical health. And with the development of the times, this unique national culture continues to get rid of its bad fear and adapt to the changing human society.

First of all, it is necessary to form a broad sense of social identity for national traditional sports. After the promulgation of the National Fitness Program (2016-2020), under the continuous publicity and guidance of the government and social organizations, a nationwide fitness boom has been formed, and the number of people taking Wushu and other national sports methods has increased significantly. As a native sports culture in China, it embodies a strong sense of national identity. On the one hand, through the popularization of the culture of sports healthy nation, it not only enhances the public's strong desire to exercise and enhance their physique, but also greatly improves the national cohesion.

Secondly, we should set up the Chinese standard of sports health, and show Chinese health characteristics and profound connotation. In the 21 st century, with the deepening of globalization, the development of sports culture must conform to the characteristics of the development of the times, especially in the process of realizing the Chinese dream and realizing the great rejuvenation of the Chinese nation, we must show the image of a big country and set up Chinese standards. To set up the Chinese standard of sports health is not only the inheritance and development of our excellent traditional culture, but also the promotion of sports health culture and the recognition of our Chinese nation. The development of history has proved that only by taking the road of socialism with Chinese characteristics, inheriting and carrying forward the excellent traditional culture of the Chinese nation, can we finally become a powerful socialist country.

\subsubsection{Deepen the Connotation of National Traditional Sports and Enrich the Spiritual Content of Traditional National Sports Fitness}

China's national traditional sports has a long history. It is created by the working people in the process of historical development. Its content is constantly enriched and improved. Its connotation endows the characteristics of national culture and shows the distinctive national characteristics and traditional moral concepts. At the same time, it pays attention to the improvement of the physical ability of the traditional people and the improvement of their physical ability. Traditional national sports, as a product of historical crystallization, has proved that it plays a special role in enhancing national pride and national cohesion. In the hundred year history of humiliation, many national heroes have come forward to prove the integrity of our Chinese people with their strength in the face of imperialist provocation, which has greatly stimulated national emotions and defended physical self-esteem [15]. These are the confirmation of national traditional sports and their value, and we need to focus on exploring them.

It is an important task for our country to excavate the connotation of national traditional sports and enrich the spiritual content of national traditional sports fitness in the new era of socialism with Chinese characteristics and the strategy of healthy China. Our national traditional sports are rich and colorful with different forms. There are no special requirements for equipment and venues. There are different sports items for different ages, which have absolute advantages in comprehensive fitness. At present, we need to deepen the connotation of national traditional sports from many aspects, rather than shallow understanding. While excavating the connotation, it must be combined with the background of the times, conform to the needs of people's physical and mental health, and inject the connotation of the times into the connotation of traditional national sports. While excavating its own culture, we must continue to expand our external exchanges. Especially in the context of globalization, we must absorb the external essence and enrich the spiritual content of our traditional sports fitness.

\section{Conclusion}

In this paper, under the background of healthy China, this paper studies the problem of national traditional sports fitness, and holds that the strategy of healthy China objectively requires Chinese people to master the basic characteristics of national traditional sports and the spirit of national culture, and establish a sound and effective fitness mechanism in line with the characteristics of national culture; by strengthening the top-level design of sports health, the public fitness system of national traditional sports can be constructed and developed The industry of sports health era should scientifically position the national traditional sports fitness activities with sports prescription, so as to carry forward the national sports culture, enrich the spiritual content of national traditional sports fitness, and achieve the overall shaping of national traditional sports fitness. Only in this way can we gain better international recognition, show the style of a big country, set up Chinese standards, and enhance our national cohesion.

\section{Acknowledgements}

Supported by "General project of humanities and social sciences of Sichuan education department in 2018. (project no: 18SB0702)". 


\section{References}

[1] Cui Yongsheng, Si Hongyu. Discussion on the cultural confidence of Qigong from the perspective of cultural identity [J]. Journal of Hebei Institute of physical education, 2019 (4): 87.

[2] Li Hongwen. Ethical basis of healthy China [J]. Morality and civilization, 2019 (6): 152-177.

[3] Wu Haiying. The only way to promote college students' physical health: a good lifestyle [J]. Sports science and technology, 2017 (4): 141-143.

[4] Chen Zhu, Gao Qiang. Taking the path of health reform and development with Chinese characteristics to enable everyone to enjoy basic medical and health services $[\mathrm{J}]$. China health industry, 2008 (3): 18-21.

[5] Li Tao, Wang Xiufeng. Connotation and realization path of healthy China [J]. Health economics research, 2016 (1): 4-10.

[6] Peng Guoqiang. American sports health promotion service system and Its Enlightenment to healthy China [J]. Sports and science, 2016 (5): 112-120.

[7] Han Xiping, sun Xiaojie. Comprehensive implementation of healthy China strategy [J]. Frontline, 2018 (12): 54-57.

[8] Liu changjiao. Research on the health value of national traditional sports under the background of "Healthy China" [J]. Chinese character culture, 2019 (20): 176.

[9] Chi Qingrui. Research on the role and value of national traditional sports in national fitness activities $[\mathrm{J}]$. Contemporary sports science and technology, 2020 (4): 201.

[10] Luo Yimin, Jiang Dongsheng. Classification of Chinese traditional sports [J]. Journal of Shandong Institute of physical education, 2008 (8): 38.

[11] Zhao Su Zhe. Classification and development of national traditional sports [J]. Sports journal, 2007 (5): 79.

[12] Wang Yucheng. Research on winter fitness characteristics and Countermeasures of the elderly population in Northeast China [J]. Modern economic information, 2016 (23): 487.

[13] Yao Huibo. Research on collaborative development mechanism of folk sports and national fitness [J]. Journal of Hebei Institute of physical education, 2017 (5): 93.

[14] Yang zhongbing, Wang Jiangping. Research on the dilemma and breakthrough path of traditional ethnic sports in Guizhou Province from the perspective of global economic integration [J]. Guizhou ethnic studies, 2019 (5): 156.

[15] Wang Junpeng, Hu Anyi. Analysis on the mechanism of body self-esteem promoting the teaching of national fitness dance $[\mathrm{J}]$ Journal of Hubei Normal University (NATURAL SCIENCE EDITION), 2014 (4): 107-108.

\section{Biography}

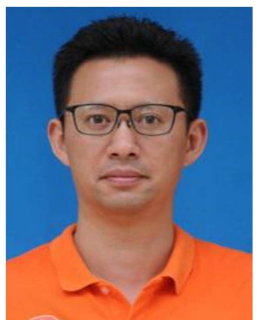

Zhu Chunquan, 1979.12--, associate professor, master of education; research direction: physical education teaching theory, sports policy and sports theory, sports training, etc; Company: Sichuan Vocational and technical college, sports department, Suining, Sichuan, China. 